PROFESIONALES Y HERRAMIENTAS PARA EL DESARROLLO LOCAL Y SUS SINERGIAS TERRITORIALES. EVALUACIÓN Y PROPUESTAS DE FUTURO IX Coloquio Nacional de Desarrollo Local del GTDL-AGE 

ANTONIO MARTÍNEZ PUCHE, XAVIER AMAT MONTESINOS, ISABEL SANCHO CARBONELL y DANIEL SANCHIZ CASTAÑO (EDS.)

\section{PROFESIONALES Y HERRAMIENTAS PARA EL DESARROLLO LOCAL Y SUS SINERGIAS TERRITORIALES. EVALUACIÓN Y PROPUESTAS DE FUTURO}

IX Coloquio Nacional de Desarrollo Local del GTDL-AGE

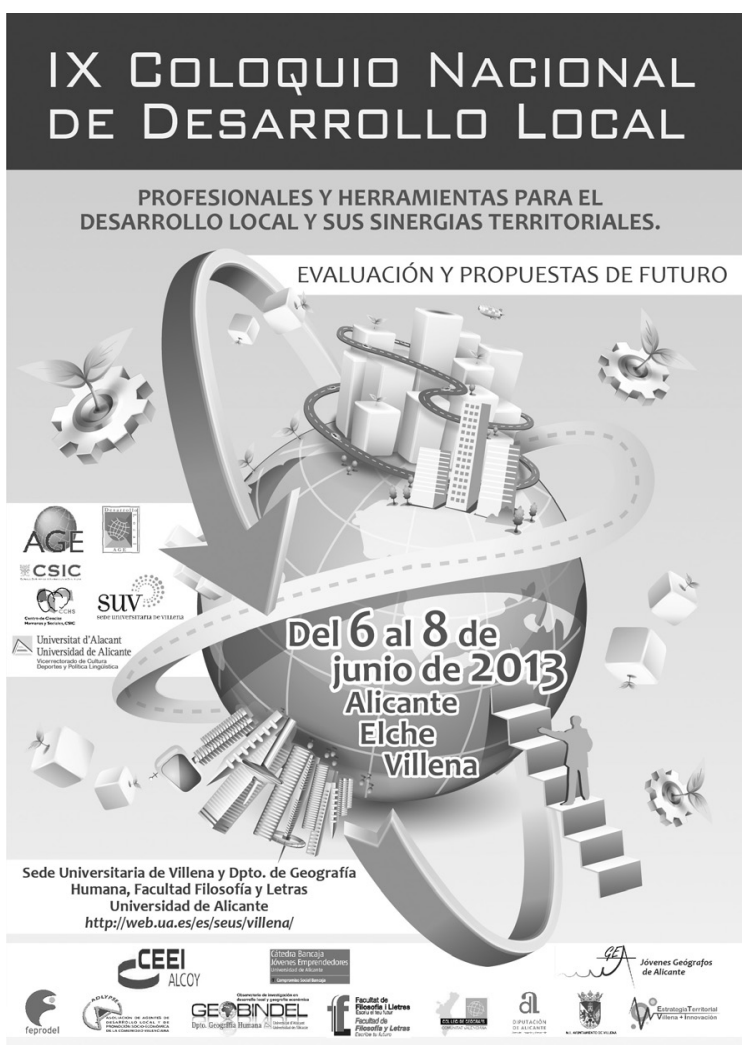


Este libro ha sido examinado y valorado por evaluadores ajenos a la Universidad de Alicante, con el fin de garantizar la calidad científica del mismo.

Publicacions de la Universitat d'Alacant

03690 Sant Vicent del Raspeig

Publicaciones@ua.es

http://publicaciones.ua.es

Telèfon: 965903480

(C) Antonio Martínez Puche, Xavier Amat Montesinos,

Isabel Sancho Carbonell y Daniel Sanchiz Castaño (eds.), 2016

(C) d'aquesta edició: Universitat d'Alacant

ISBN: 978-84-16724-00-0

Dipòsit legal: A 92-2016

Disseny de coberta: candela ink

Composició: Página Maestra (Miguel Ángel Sánchez Hernández)

Impressió i enquadernació: Guada Impresores

\section{unte \\ Unión de Editoriales
Universitarias Españolas \\ WWW.une.es
WWA}

Esta editorial es miembro de la UNE, cosa que garantiza la difusión y comercialización nacional y internacional de sus publicaciones.

Reservados todos los derechos. Cualquier forma de reproducción, distribución, comunicación pública o transformación de esta obra sólo puede ser realizada con la autorización de sus titulares, salvo excepción prevista por la ley. Diríjase a CEDRO (Centro Español de Derechos Repográficos, www.cedro.org) si necesita fotocopias o escanear algún fragmento de esta obra. 


\title{
LA ESTRATEGIA TERRITORIAL DE VILLENA+ INNOVACIÓN (ETV+i), PROCESO VERSUS PROYECTO. UN MODELO DE DIAGNÓSTICO PARTICIPATIVO PARA LA CIUDADANÍA
}

\author{
Antonio Martínez Puche \\ Dpto. Geografía Humana, Universidad de Alicante1 \\ (antonio.martinez@ua.es) \\ Salvador Martínez Puche \\ Dpto. de Información y Documentación. Univ. de Murcia \\ (salvador.mpuche@gmail.com) \\ Joaquín Palací Soler \\ Dpto. Geografía Humana, Universidad de Alicante \\ (palacisoler@gmail.com) \\ Vicente M. Zapata Hernández \\ Departamento de Geografía. Universidad de La Laguna \\ (ujivzapata@gmail.com)
}

\section{RESUMEN}

La ETV+i, Villena ha iniciado un proceso, a medio y largo plazo, y un procedimiento, metodología de trabajo aplicada, flexible y participativa, para generar un diagnóstico y una herramienta ciudadana (el Foro Económico y SocialFES). Surge no sólo como un documento estratégico, sino como un instrumento abierto e inductivo a partir de una reflexión previa y un análisis participado (talleres) para generar espacios de encuentro y aprendizaje colectivo y cooperativo. Esto permitirá establecer un protocolo de objetivos y acciones,

1 Proyecto GV/2014/085: "Análisis de la innovación territorial, gobernanza y procesos de resiliencia en la Comunidad Valenciana para el favorecimiento de emprendimientos locales. Identificación de instrumentos, evaluación de indicadores y sistematización de buenas prácticas", Conselleria de Educación Cultura y Deporte, Dirección General de Universidades, Estudios Superiores y ciencia. 
facilitando a la ciudadanía su seguimiento y evaluación a la hora de definir las líneas básicas que guíen la gestión socioeconómica del municipio bajo un enfoque integrado (bottom up). El estudio y análisis propositivo se ha basado en talleres sectoriales, asambleas ciudadanas, constitución del grupo gestor del FES, realización de jornadas y seminarios, comunicación mediática y difusión a través de un blog.

Palabras Clave: Proceso participativo, Foro Económico y Social (FES), compromiso ciudadano, estrategia territorial, metodología flexible, planificación estratégica, Universidad.

\section{THE TERRITORIAL STRATEGY DE VILLENA+ INNOVATION (ETV+i), PROCESS VERSUS PROJECT. A MODEL OF PARTICIPATORY DIAGNOSIS FOR THE CITIZENSHIP}

\section{AbSTRACT}

ETV+i, Villena has begun a process, to half and I release term, and a procedure, applied work methodology, flexible and participatory, to generate FODA (the Economic Forum and Social-faiths) tool. It is not only a strategic document, It is an open and inductive instrument starting from a previous reflection and an analysis participated (shops) to generate encounter spaces and collective and cooperative learning. This will allow establishing a protocol of objectives and actions, facilitating to the citizenship their pursuit and evaluation when defining the basic lines that guide the socioeconomic management of the low municipality an integrated (bottom up) focus. The study and analysis have been based on shops, civic assemblies, and constitution of the group agent. We have done seminars, communication and diffusion through a blog.

Key Words: Process participatory, Economic and Social Forum, civic commitment, territorial strategy, flexible methodology, strategic planning, University

\section{INTRODUCCIÓN}

En el contexto actual de cambios, los territorios han de plantear estrategias renovadas e instrumentos de reflexión, proposición y acción diferentes, tomando como referencia los recursos territoriales y como herramientas el conocimiento, la experiencia, la creatividad y la innovación. En estos procesos la inteligencia territorial asume un papel importante frente a la localización convencional de inversiones; la gobernanza frente a los gobiernos tradicionales; el proyecto frente al folleto; la participación proactiva y participada de la ciudadanía frente a la asistencia pasiva de los ciudadanos. No se vive solo del diagnóstico de las potencialidades que tienen los territorios, sino del conocimiento, del 
aprendizaje compartido y del análisis de sus capacidades para poner en marcha actuaciones planificadas que determinen una hoja de ruta o agenda que consiga hacerlos más competitivos en un entorno global. Y todo ello sin menoscabo de aspectos como la democracia participativa, la calidad de vida, la revalorización monumental, cultural e identitaria, la preservación y fomento de la sostenibilidad ambiental, la potenciación y diversificación de la economía local, la mejora de los servicios y equipamientos públicos, etc.

Esta necesaria renovación es la que fundamenta la Estrategia Territorial de Villena (ETV+i), en el marco del Decreto 1/2011, de 13 de enero del Consell, que dio luz verde a la Estrategia Territorial de la Comunidad Valenciana. La normativa autonómica insta a las administraciones locales a realizar planes de acción para establecer objetivos, metas, principios y directrices en la ordenación del territorio regional. Todo ello ajustándose a la realidad de cada municipio, impulsando la participación ciudadana y aplicando instrumentos innovadores de carácter socioeconómico, ambiental, cultural y político: "El eje del Vinalopó es un territorio de fuerte tradición industrial, con una gran capacidad empresarial para desarrollar innovaciones y adaptarlas a los productos y procesos que se producen en la zona. Esta base industrial es estratégica para la provincia y la Comunitat Valenciana, por lo que debe ser potenciada mediante la incorporación de valor añadido e innovación a sectores característicos de la zona como el calzado, la piedra natural o los materiales de construcción".

Se trata, entonces, de apoyar activamente los procesos de participación e interacción democrática, no limitándose a los sujetos con organizaciones consolidadas (sindicatos, asociaciones de vecinos, entidades culturales, cooperativas, etc.), sino haciendo posible también la participación de los colectivos informales y de la ciudadanía en general. Hemos establecido discursos heterogéneos adaptados a las características del público objetivo, atendiendo a su perfil sociodemográfico y profesional, ya que en ocasiones los contenidos y el vocabulario de la planificación del territorio pueden no ser entendidos plenamente. En los talleres hemos diferenciado mensajes y metodologías porque no es lo mismo dirigirse a colectivos de amas de casa, jubilados, jóvenes, funcionarios municipales o empresarios, intentando implicar así al mayor número de actores y entidades para afianzar un sentimiento de pertenencia a un proyecto colectivo. La estrategia de comunicación en los medios locales promoviendo la "acción común" ha sido en este sentido un factor primordial. La participación pública se entiende como el procedimiento que permite a una sociedad incidir y formar parte en la toma de decisiones sobre políticas que le conciernen: medio ambiente, servicios, cultura, educación, sanidad, inmigración, etc. En las administraciones públicas, sobre todo a nivel local, esto supone tres importantes cambios: incidir en los contenidos y prioridades, modificar las formas de adoptar las políticas públicas y cambiar las formas en la aplicación de las mismas. En efecto, la búsqueda de la calidad de vida de los ciudadanos a través de una gobernanza responsable y comprometida, 
que vaya al encuentro de un desarrollo participado y sostenible (en lo ambiental, socioeconómico y cultural), exige una obligada revisión de las políticas y los mecanismos actuales. Además, requiere de la aplicación de sólidos principios que mejoren el acceso no solo a la información, sino a todo el proceso decisorio de forma conjunta, obligando a buscar canales adecuados para que las demandas vecinales se puedan hacer efectivas. Si no la participación se convierte en la "práctica del mucho decir y del poco decidir y hacer".

\section{OBJetivos}

En abril de 2012 comenzó la ETV+i, un proyecto financiado por el Ayuntamiento de Villena que coordina el Departamento de Geografía Humana de la Universidad de Alicante. Pronto nos dimos cuenta de que no tenía que ser un diagnóstico al uso ni un estudio descriptivo más, como ha ocurrido en otros casos. La inflación de planes estratégicos desarrollados en la provincia de Alicante obligó a finales de ese mismo año a celebrar una reunión para optimizar las iniciativas impulsadas a instancias de distintos organismos: Universidad de Alicante, Cámara de Comercio, Coepa y Diputación provincial, entre otros. El exceso de documentos estratégicos había provocado una notable parálisis en las acciones propuestas ${ }^{2}$. Tampoco había ayudado la aparente desconexión con las realidades del territorio, la ausencia de protagonismo de la ciudadanía, los elevados costes de algunos proyectos presentados y el interés partidista de ayuntamientos y demás instituciones. En este escenario aparecieron sendos planes estratégicos en los municipios de Elche (2011) y Alicante (2012) que no han contribuido a considerar la planificación estratégica como un instrumento eficaz y eficiente, útil y no solo utilitarista. De hecho, la percepción general es que muchos de estos documentos han servido para realizar un diagnóstico descriptivo, sin proposiciones coherentes ni acciones proactivas ni una verdadera participación pública y ciudadana ${ }^{3}$.

La ETV+i incluye entre sus objetivos conciliar algunas de las directrices de la Estrategia Territorial de la Comunidad Valenciana, y sus previsiones para las comarcas del Vinalopó, con los planteamientos derivados del ámbito local villenense. También ha contemplado fomentar, a partir de las futuras proposiciones, un territorio más competitivo en lo económico, más respetuoso en lo ambiental y más cohesionado e integrador en lo social, generando por tanto un valor añadido. No hay que olvidar que Villena es el segundo término municipal

2 "Los expertos apuestan por revisar los planes estratégicos para reactivar la provincia. El urbanista Alfonso Vegara y los catedráticos Andrés Pedreño y Joaquín Melgarejo abogan por impulsar proyectos e ideas que no requieran grandes inversiones " Diario INFORMACIÓN, Sábado 10 de noviembre de 2012

3 Impulsa Alicante. Diagnóstico competitivo y grado de desarrollo de la ciudad de Alicante (2012), Deloitte y Ayuntamiento de Alicante, 321 p.; Elche. Proyecto Ciudad (2011), Fundación Metrópoli y Ajuntament d' Elx, 233 p. 
más grande de la provincia de Alicante $\left(345 \mathrm{Km}^{2}\right)$, y que junto a un sistema productivo basado tradicionalmente en la fabricación de calzado, también la agricultura y, sobre todo, los servicios juegan un papel de notable relevancia en la economía local ${ }^{4}$.

A lo largo de este año y medio, los análisis, diagnósticos, talleres, jornadas, coloquios y asambleas ciudadanas que ha llevado a cabo el equipo de la Estrategia se han inspirado en los siguientes objetivos:

- Detectar, identificar y diagnosticar las necesidades reales y potenciales del municipio, agrupándolas por áreas de gestión: economía y empleo, turismo y patrimonio, medio ambiente y agricultura, urbanismo e infraestructuras, gobernanza y ciudadanía, etc.

- Sistematizar la documentación recopilada y aportada por las entidades públicas y privadas para establecer un informe final que contenga propuestas de actuación con criterios de eficiencia y eficacia (con posterior desarrollo en planes generales y especiales a nivel municipal).

- Propiciar la reflexión colectiva y compartida en torno al modelo territorial y a la acción de gobierno, implicando a la ciudadanía, los sectores privados y los poderes públicos locales en todo el proceso.

\section{Metodología}

La metodología aplicada ha sido ad hoc, con un marcado carácter innovador, flexible y experimental, dando lugar al desarrollo de investigación-acción-participación, en el que se ha pretendido favorecer espacios de encuentro y aprendizaje, entre ciudadanía, políticos y Universidad (figura 1).

En primer lugar se ha efectuado una recopilación y una síntesis analítica de los proyectos realizados desde los años 80 hasta ahora, estableciendo un catálogo documental (panel de experiencias) que pudiera ser útil en el diagnóstico previo. Destacan los Planes Estratégicos Locales y Provinciales, además del análisis de la documentación aportada por algunas personas que intervinieron en tres iniciativas de implantación de estructuras similares a los Consejos Económicos y Sociales de la ciudad desde 1984. También se han tenido en cuenta el Plan Especial del Casco Histórico de Villena, el Plan Revita y el Plan Especial de la Huerta. A su vez se han analizado otros proyectos sectoriales, como el Proyecto de Integración del Ferrocarril y el estudio de la Estación del AVE de Villena, el Plan de Dinamización de Producto Turístico (PDPT), el programa de "participación ciudadana", el Pacto de Gobierno (2011-2015) y el Plan Municipal de Igualdad.

4 En el anuario municipal de Caja España de 2012, los datos relativos a la distribución por ocupación en Villena en 2012 son los siguientes: agricultura, 6'5\%, industria 28 ' $7 \%$; construcciones $12^{\prime} 1 \%$; servicios $52^{\prime} 7 \%$ ) 
Para sistematizar la información obtenida se ha confeccionado una ficha de análisis con estos apartados: Motivación (Por qué), Objetivos (Para qué), Metodología (Cómo se hace), Contenidos (Qué es lo que se ha hecho hasta ahora), Resultados (Qué es lo que se ha conseguido), Conclusiones (Valoraciones).

La intención ha sido tener una idea global del municipio, más allá de las meras cifras estadísticas y socioeconómicas que suelen utilizar habitualmente las consultoras foráneas en sus planificaciones estratégicas convencionales. En ellas se detecta un desconocimiento de las circunstancias reales de los municipios objeto de evaluación.

\section{Espacios de diálogo entre investigadores, ciudadanía y responsables políticos}

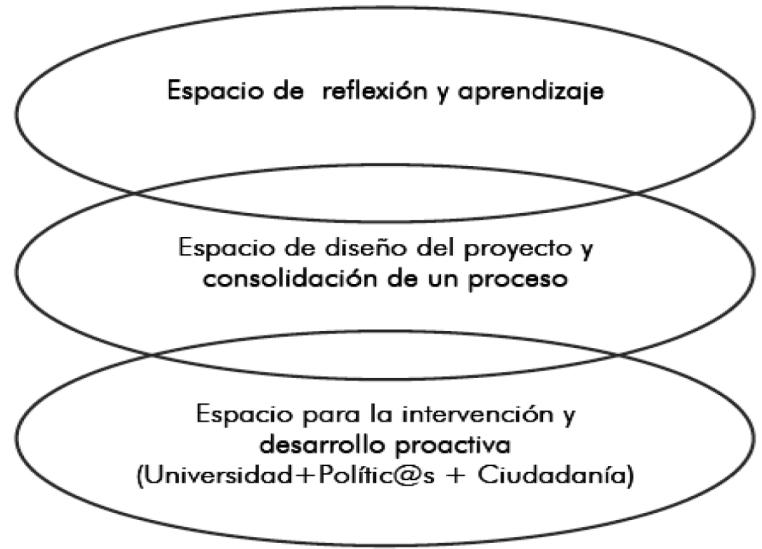

Figura 1. Esquema de la metodología "Investigación-Acción” en las Estrategia Territorial de Villena + Innovación.

Fuente: Elaboración propia.

En segundo lugar se está aplicando un sistema de indicadores que medirá la capacidad de innovación de las empresas, la calidad de vida de los ciudadanos, el grado de pertenencia a un lugar, el papel de la identidad cultural, las infraestructuras verdes, los niveles de participación pública en la sociedad, etc. De este modo se identifican y definen las oportunidades de innovación territorial de Villena para reforzar desde el punto de visto cuantitativo los aspectos cualitativos extraídos en los talleres participativos y las asambleas ciudadanas. En efecto, la ciudadanía también ha asumido de forma voluntaria un papel activo por medio de convocatorias abiertas y sectoriales a las que han acudido personas y colectivos de todo tipo. El motivo es lograr un doble proceso: obtención de datos (talleres/ entrevistas/jornadas) y determinación de prioridades y necesidades (asambleas 
ciudadanas), generando al mismo tiempo una mayor implicación en el desarrollo de la ETV+i. En este sentido, no se plantea un diagnóstico ajeno a la población, sino implementar un instrumento que dote al proyecto de continuidad a través de la constitución de un futuro Foro Económico y Social de Villena (FES). En febrero de 2013, coincidiendo con la $4^{\mathrm{a}}$ asamblea ciudadana celebrada en el Gabinete de Desarrollo Económico (La Tercia), un grupo de 11 vecinos y vecinas de Villena se postularon voluntariamente para preparar el borrador de reglamento del nuevo organismo ciudadano a lo largo de seis meses. La concepción participativa y participada (bottom up) de la ETV+i facilita una visión transversal y global de la gestión municipal. Asimismo establece relaciones con distintos sectores sociales (ciudadanos e institucionales) y aprovecha diversas herramientas metodológicas.

La intervención de la ciudadanía en el proceso de elaboración de la Estrategia Territorial de Villena+ Innovación se ha materializado en una serie de talleres participativos con una metodología ágil, innovadora, fácil de aplicar y adaptada a las necesidades del territorio.

a) Encuestas abiertas y cerradas. Esta técnica ha permitido producir y organizar con bastante rapidez un conjunto amplio de ideas sobre diversas temáticas (urbanismo, entidades sociales, economía, equipamientos, prospectiva de ciudad). La dinámica se ha dividido en tres partes. En un primer momento se distribuía a los participantes en grupos. A continuación debatían sobre el asunto expuesto. Por último, el moderador general exponía en un panel a todos los asistentes las conclusiones de cada grupo acerca de los aspectos positivos o negativos y las propuestas de cambio o nuevas propuestas.

b) Focus group. Ha servido para fomentar el dialogo en pequeños grupos sobre un tema específico. Generalmente esta dinámica se ha realizado con colectivos que a priori conocían de primera mano el tema que se iba a debatir, bien porque eran miembros de una asociación vinculada con el asunto o bien porque trabajaban en su día a día esas cuestiones. Ello ha fomentado una fuerte interacción entre todos los miembros, produciendo un efecto sinérgico que desencadena un aluvión de respuestas y una lluvia de ideas entre todos los presentes.

c) Elevator pitch. Se trata de plantear, en menos de un minuto, las principales ideas que se les ocurrían a los participantes en relación con la pregunta realizada. La dinámica del taller de participación ha seguido este patrón. En primer lugar cada participante exponía al resto de asistentes su visión del municipio, teniendo en cuenta el pasado, el presente y la idea de ciudad que querían para el futuro. Luego se dividían en tres grupos de cuatro participantes compuestos por representantes de un partido político o de un colectivo asociativo distinto. Cada grupo plasmaba de manera consensuada y en una ficha aquellos aspectos claves para el desarrollo social, territorial y económico de Villena. Finalmente el portavoz de cada grupo exponía al resto de asistentes las ideas reflejadas. 


\section{Cuadro 1. Ficha Técnica de los talleres}

\begin{tabular}{|l|l|}
\hline Universo de estudio & $\begin{array}{l}\text { Jóvenes, técnicos municipales, asociaciones } \\
\text { (sociosanitarias, festeras, culturales, vecinales, } \\
\text { etc.), tejido socioeconómico (empresas, sindicatos, } \\
\text { cooperativa, etc.) }\end{array}$ \\
\hline Ámbito geográfico & Villena \\
\hline Elemento de análisis & Grupos de trabajo 4-5 personas \\
\hline Tamaño muestral & $\begin{array}{l}65 \text { grupos de trabajo } \\
315 \text { personas }\end{array}$ \\
\hline Información recogida & $\begin{array}{l}\text { Opiniones sobre la función del municipio en la } \\
\text { comarca, elementos objeto de atención especial y } \\
\text { acciones necesarias para el municipio }\end{array}$ \\
\hline Trabajo de campo & Mayo y octubre de 2012 \\
\hline
\end{tabular}

Fuente: Elaboración propia.

d) Mapas mentales y de percepción. Los mapas mentales son un método muy eficaz para extraer información de manera sintética. Se trata de en un método lógico y creativo para expresar ideas que consiste, literalmente, en cartografiar las reflexiones sobre un tema. En este caso se han utilizado en los talleres realizados con los jóvenes estudiantes de Bachillerato, que han podido ilustrar su percepción de los principales elementos del municipio a través de símbolos, palabras e imágenes.

Por otra parte, se trata de un enfoque flexible ya que no es un método cerrado y fijo, sino que tiene capacidad de adaptación para transformarse y dar respuesta a las novedades que van surgiendo, incorporándolas de un modo sistemático. Así se cuenta con aquellos elementos que pueden ser útiles y enriquecedores.

La comunicación ha cumplido cinco funciones esenciales: garantizar la transparencia de todo el proceso, informar y dar a conocer las acciones llevadas a cabo, concienciar a través de la explicación, incitar a la reflexión y, finalmente, lograr el compromiso de la población motivándola a participar en una iniciativa fundamental para consolidar la convivencia y la planificación futura del municipio. Se han convocado cuatro ruedas de prensa y se han difundido 25 notas de prensa en los medios locales y comarcales ${ }^{5}$ (dos diarios en versión impresa y digital, dos emisoras de radio y una televisión comarcal), además de otros medios provinciales. Asimismo se ha creado un blog de la ETV+i en el que se han recogido todas las informaciones, actuando como cauce de inte-

5 Por ejemplo, en El Periódico de Villena (EPDV) se han contabilizado 9.200 entradas a las noticias referidas a la ETV+i y al FES, con una media de 438 visitas por publicación. 
racción con los destinatarios. Y se han utilizado las redes sociales y el correo electrónico, con más de 250 direcciones, para convocar a la ciudadanía a cada taller y asamblea.

\section{Contenido DE LA ETV+I}

La Estrategia Territorial de Villena + innovación $(\mathrm{ETV}+\mathrm{i})$ pretende ser un instrumento flexible e inductivo y, por tanto, sometido a la dinámica social, económica, ambiental y cultural del municipio que permita una acción de gobierno programática y sistemática (planificada) a partir de un proceso previo de reflexión compartido y análisis participado. Ello puede ayudar a establecer un protocolo de actuación de objetivos y acciones, facilitando a toda la ciudadanía someterlo a una evaluación y seguimiento para definir las líneas básicas que guiarán la gestión socioeconómica en el municipio bajo un enfoque integrado.

En este sentido la ETV+i se estructura en áreas temáticas para el estudio y análisis propositivo, participativo y aplicado, a lo largo 2012 y 2013, apoyándonos en la transparencia y la comunicación (medios de comunicación, actividades formativas, reuniones sectoriales y blog${ }^{6}$ ).

Entre los talleres realizados a jóvenes, tejido asociativo, sectores socioeconómicos y técnicos municipales, destaca el papel que el municipio puede ocupar en la comarca del Alto y Medio Vinalopó. En cuanto a los elementos a conservar y reforzar, los elegidos en primera opción son el centro histórico, los polígonos industriales, los espacios naturales y el turismo, como una actividad que se debe posicionar mejor que lo está en la actualidad. Y entre las acciones necesarias, en primera instancia destacan las de tipo instrumental vinculadas a la ordenación del territorio (como los Planes Generales de Ordenación Urbana y las de preservación y gestión de los recursos naturales) y las de tipo socioeconómico, como las del fomento de nuevos yacimientos de empleo, apoyo al emprendedor y reactivación del empleo (cuadro 2).

No obstante, del contenido de los talleres podríamos destacar los siguientes resultados generales:

a) La necesidad de que haya continuidad en la gestión del gobierno municipal, ya que la alternancia de las últimas cuatro legislaturas, un gobierno diferente cada cuatro años, no ha podido consolidar una línea de trabajo en los proyectos previstos. A ello hay que añadir la falta de liderazgo político.

b) La apuesta por una diversificación de las actividades económicas (agricultura, turismo, patrimonio, comercio, nodo empresarial, etc.).

c) La aplicación y generación de instrumentos y herramientas de gestión municipal (PGOU, coordinación de iniciativas de los servicios municipales, Plan Integral de la Huerta, etc.).

6 http://www.etvi.villena.es/ 
d) Revalorización del entorno y gestión de los recursos territoriales (optimización de los recursos municipales, abastecimiento y racionalización de la explotación de los acuíferos, residuos y basuras, etc.) que doten de coherencia la gestión de los recursos locales y del territorio.

e) Que se tenga más en cuenta a los ciudadanos, a través de la participación y de una mayor implicación de la ciudadanía. No solo cuando llegan elecciones.

Cuadro 2. Función que puede cumplir el municipio de Villena en el contexto de las comarcas del Vinalopó (Alicante)

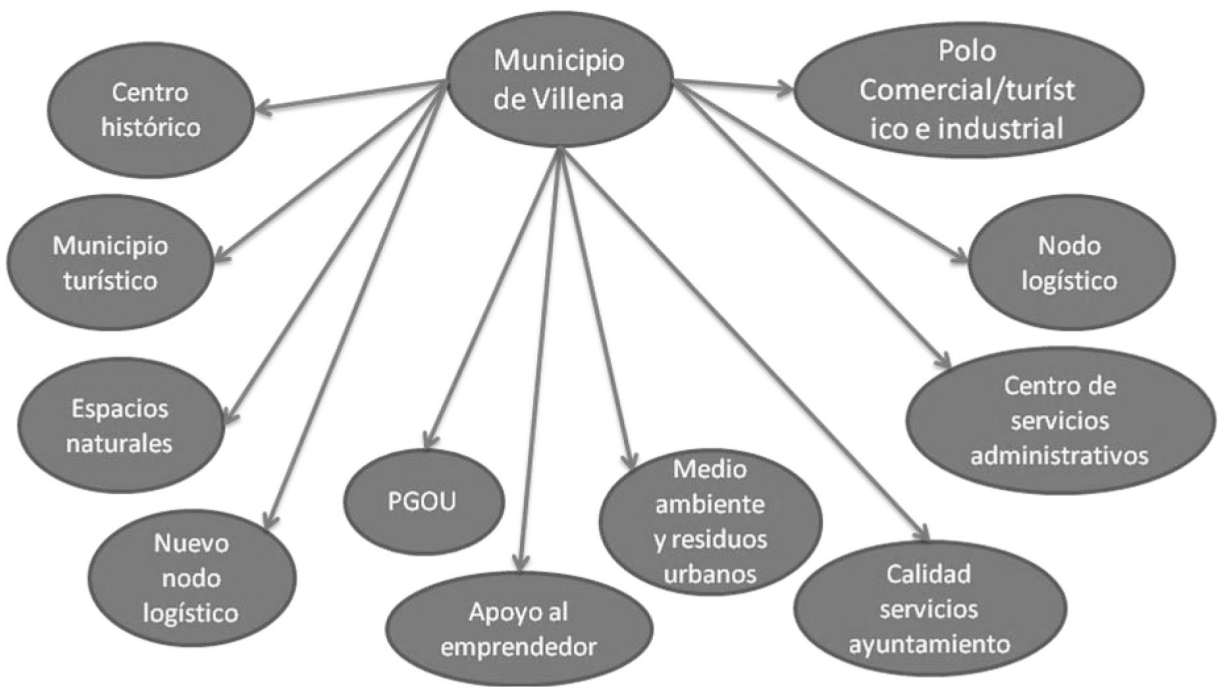

Fuente: Elaboración propia.

4.1. La constitución de un Consejo Económico y Social en Villena, desde la participación ciudadana

En la $4^{\mathrm{a}}$ asamblea ciudadana celebrada en el marco de la ETV+i, se estableció crear un Consejo Económico y Social como órgano autónomo, consultivo, propositivo y representativo de todos los ciudadanos de Villena. Para ello se eligió al grupo gestor del futuro Foro Económico y Social (FES). En las anteriores reuniones de trabajo, realizadas desde julio de 2012 hasta febrero de 2013, se había evidenciado la necesidad de este órgano municipal. Las diferentes convocatorias abiertas, no solo representativas, se realizaron a través de mailing, acudiendo una media de 60 vecinos y vecinas en cada una de ellas. En estas fases preliminares a la asamblea de febrero se detectó la conveniencia de cambiar las cosas, poniéndose de manifiesto el sentimiento ciudadano de que ninguno sobraba en este proceso. Así, bajo la tutela y acompañamiento del pro- 
fesor Vicente Zapata, de la Universidad de la Laguna, se empezaron a definir los atributos del futuro Consejo Económico y Social del municipio, los pasos a seguir en este proceso ciudadano, su utilidad y finalidad. Algunos términos que resumen las propuestas presentadas son: voluntario, transparente, abierto, actitud positiva, acuerdos, coherencia, conciliación, confianza, constancia, diálogo, esperanza, generosidad, utilidad, voluntad, integración.

En una de las sesiones, distribuidos por grupos, la ciudadanía debatió, reflexionó, propuso y respondió a seis preguntas, compartiendo las conclusiones con el resto de asistentes a través de sus portavoces.

A la primera pregunta de ¿a qué necesidad responde una estructura orgánica ciudadana?, la contestación fue que respondía a una cierta insatisfacción general que animaba a cambiar las formas de participar en el proceso de desarrollo municipal mediante el impulso de estrategias colaborativas e integradoras. En la segunda, ¿qué ventajas reportará?, se afirmó que reportará un cauce de diálogo y acción conjunta que permitirá construir un municipio que responda a un modelo compartido. La tercera, ¿qué dificultades encontraremos?, se aludió a que habría que salvar la desconfianza, superar los intereses particulares y gestionar la frustración e impaciencia que provocan las experiencias previas.

La cuarta, ¿qué hemos aprendido de los antecedentes?, arrojó la idea de que se dispone de capital humano e iniciativa para construir nuevos procesos en los que el liderazgo compartido y la constancia aseguren la continuidad que son imprescindibles y necesarias. La quinta, ¿quién/qué entidad no debe faltar?, obtuvo la respuesta de que debe participar toda aquella persona y colectivo que desee aportar su punto de vista y su colaboración para mejorar de forma constructiva la realidad municipal, haciendo sostenible el proceso. Y a la última, ¿cómo iniciamos el proceso?, se contestó que dialogando y consensuando objetivos, procedimiento y calendario de trabajo que haga avanzar un proceso ya iniciado en el que deben seguir integrándose actores todavía ausentes.
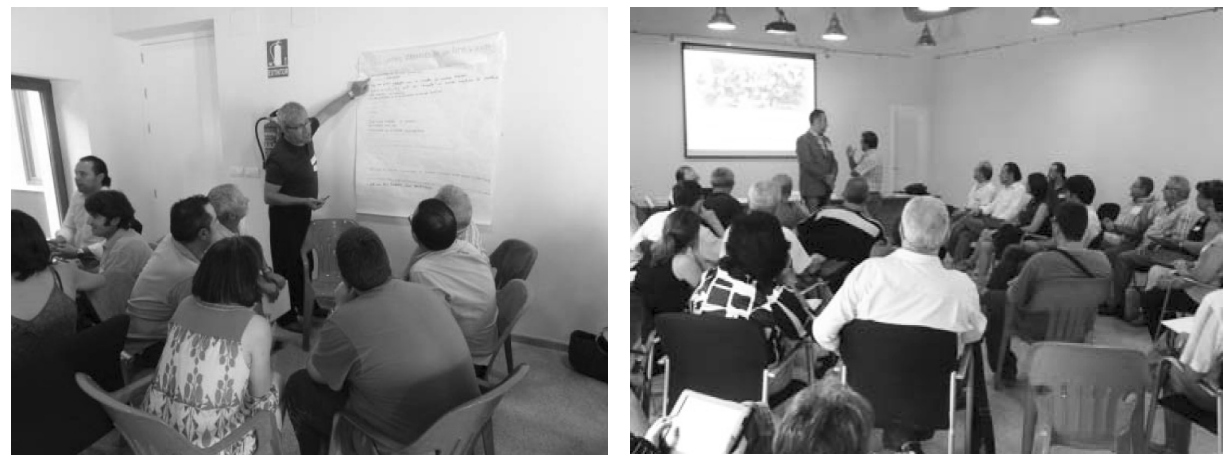

Imágenes 1 y 2. Asambleas ciudadana desde julio de 2012 hasta febrero de 2013.

Fuente: Elaboración propia. 
En la asamblea de febrero de 2013 se constituyó un grupo de trabajo para redactar una propuesta de reglamento, que será debatida y consensuada con posterioridad, en el que se recogieran los contenidos, funciones, componentes y directrices generales del Consejo Económico y Social de Villena, que finalmente se denominará Foro. Previamente se habían definido las pautas y el mecanismo de elección de los candidatos que integrarían este grupo gestor. Tenían que ser entre 8 y 12 personas, con equilibrio entre géneros, que reflejara la diversidad socioprofesional del municipio y que, en definitiva, estuvieran dispuestos a trabajar por el bien común de la ciudadanía mediante reuniones periódicas. En este caso, se fueron postulando voluntarios y voluntarias que defendieron su candidatura ante la asamblea ciudadana que los fue ratificando.

Desde febrero hasta el mes de octubre, este grupo de ciudadanos ha trabajado de forma voluntaria y muy eficazmente por su municipio. Son 11 ciudadanos y ciudadanas procedentes de sectores socioeconómicos dispares (jubilados, empresarios, autónomos, parados, funcionarios, trabajadores por cuenta ajena), de ideologías diferentes, de segmentos de edad muy diversos, pero con la misma motivación de contribuir a mejorar su ciudad. Durante todas las sesiones (más de 20 reuniones de dos horas de duración cada una de ellas), llevadas a cabo de marzo a septiembre, se ha levantado acta de los acuerdos tomados con el fin de sistematizar y evaluar los avances. En los meses de julio y agosto se han mantenido encuentros con todos los partidos políticos y sindicatos villenenses, así como con asociaciones juveniles y empresariales. Han querido hacer partícipes a estos colectivos del proceso y de la importancia de que las

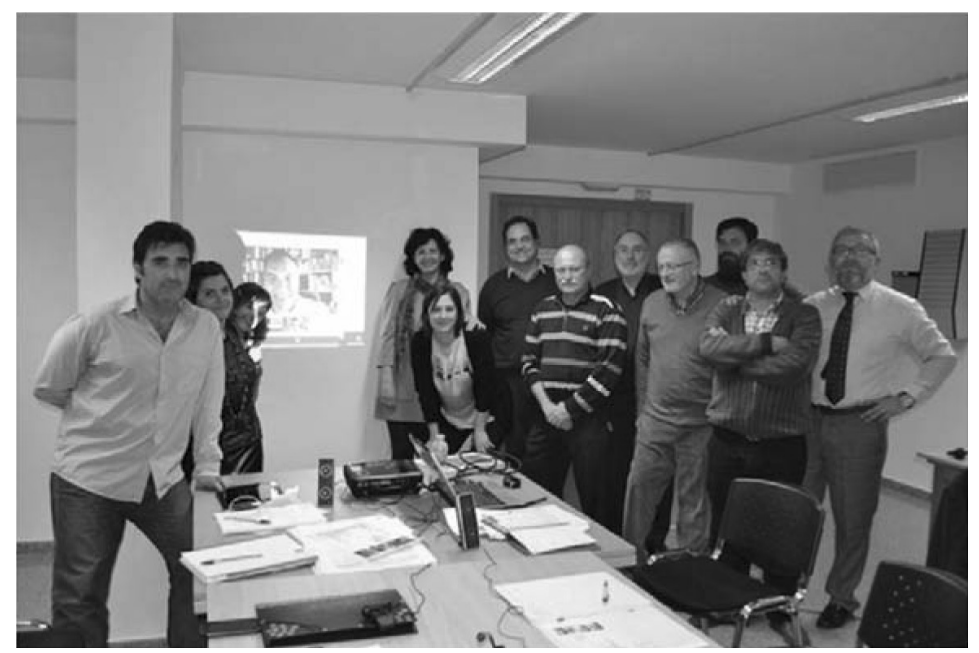

Imagen 3. Grupo gestor del Consejo Económico y Social de Villena en una reunión de trabajo en la sede universitaria Al fondo Vicente Zapata por videoconferencia.

Fuente: Elaboración propia. 
bases que sustentan el futuro Foro Económico y Social de Villena sean lo más participadas posible, buscando el máximo consenso. De algún modo, se favorece un aprendizaje colectivo, una experiencia compartida y un diálogo social entre todos los ciudadanos que voluntariamente decidan implicarse y comprometerse. No se trata de una participación por decreto o por cupo ("representatividad legitimada"), sino de un proceso abierto, flexible, original y transparente para que la ciudadanía se implique desde el principio en este proceso comunal a medio y largo plazo.

El papel de los políticos locales, sobre todo el de los que conforman la coalición de gobierno, también es destacado por su voluntad "de dejar hacer". No han interferido en ningún momento y han acompañado y participado el proceso como unos ciudadanos más en todo momento. Así se garantiza no desnaturalizar e influir en la metodología de actuación. Además, ha sido fundamental la tutorización y el acompañamiento que ha desempeñado la Universidad de Alicante, materializados en la Sede de Villena. El departamento de Geografía Humana se ha encargado de realizar ese diagnóstico participativo, ha articulado el equipo de trabajo y ha posibilitado una metodología flexible y propia. Para reforzar las acciones de comunicación, formación y la metodología participativa, se desarrollaron a finales del mes de abril unas jornadas sobre la ETV+i con el título de "Junt@s hacemos Villena". En ellas se contó con la presencia de un panel de expertos nacionales (de la Universidad de Alicante y otras instituciones académicas superiores, junto con profesionales de otras instituciones), que trataron aspectos vinculados al diagnóstico: diversificación económica, fomento del talento, turismo, actividades productivas vinculadas a los aprovechamientos agrarios, infraestructuras y equipamientos, marca ciudad, etc. Por otra parte, también se establecieron talleres con el público asistente y los componentes del grupo gestor del FES, presentándose algunos de los avances del diagnóstico establecido en la ETV+i.

\section{RESULTADOS Y CONCLUSIONES}

La ETV+i trata de favorecer un proceso genuino y diferente, que no sólo se quede en un proyecto de diagnóstico, sino que facilite un procedimiento que defina líneas estratégicas y acciones específicas, dando lugar a un proceso a medio y largo plazo. Todo ello acompañado y reforzado por el trabajo que ha comenzado el grupo promotor del Foro Económico y Social de Villena (FORO) como un organismo consultivo y ciudadano. Se ha realizado un informe final que contiene diversos capítulos: Introducción (contextualización conceptual de la iniciativa en el marco normativo de la ETCV, el desarrollo local y la innovación territorial); Memoria (explicación de los objetivos, metodología e instrumentos de la ETV+i y descripción del desarrollo, ejecución y cronograma de las acciones llevadas a cabo); Resultados (diagnóstico con 
las valoraciones cuantitativas y cualitativas organizadas por áreas temáticas de gestión municipal); Conclusiones (reflexiones finales y propuestas / líneas de actuación futuras); Anexos (documentos, gráficos, material audiovisual y fotográfico, encuestas, entrevistas, datos sobre el equipo redactor, hemeroteca (notas de prensa), etc.

Cuadro 3. Esquema sobre las fases y trabajo de la ETV+i (2012-2014)

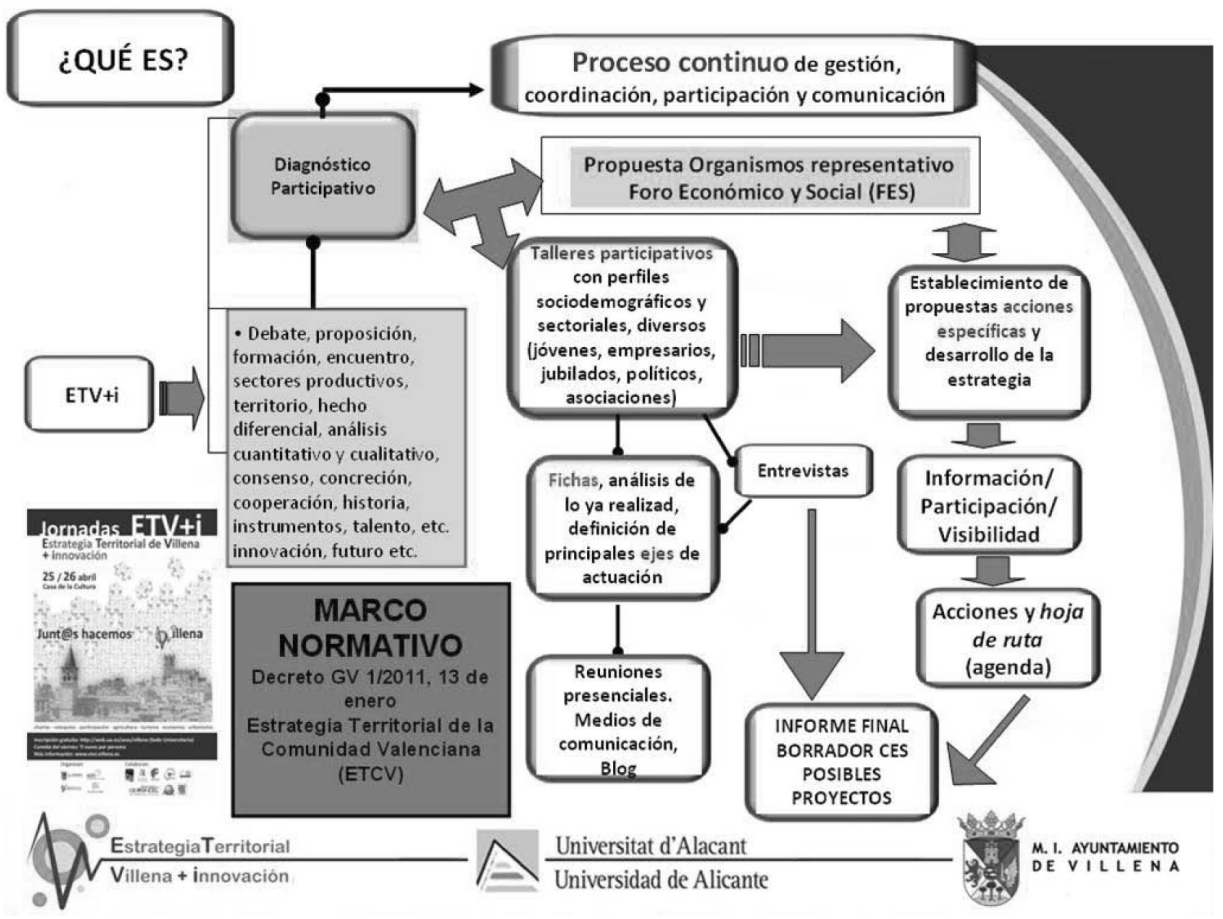

Fuente: Elaboración propia.

Estas herramientas de diagnóstico propositivo y proactivo, que se están llevando a cabo en otros municipios de la Comunicad Valenciana, han tratado de favorecer un proceso genuino y diferente, que no sólo se quedara en un proyecto de diagnóstico, sino que facilitara un procedimiento que definiera líneas estratégicas y acciones específicas, dando lugar a un proceso a medio y largo plazo. Todo ello acompañado y reforzado por el departamento de Geografía Humana de la Universidad de Alicante (junto con la sede Universitaria de Villena), que lo ha tutelado y acompañado, y con la complicidad de los políticos que han generado las condiciones necesarias, para no "manipular interesadamente" el proceso, dejando hacer. Se realizó un informe final, no sólo de diagnóstico, sino también propositivo, que contó con la participación de abajo a arriba de 
la ciudadanía. De esta forma se aplicó la metodología investigación-acciónparticipación, que encaja con las nuevas directrices exigidas en los Fondos de Cohesión Europea (2014-2020). En Villena, su estrategia participada (ETV+i) se aprobó por unanimidad en el pleno municipal (abril 2014), en los que los grupos de la oposición también votaron a favor. Además, se ha generado un Foro Económico y Social ${ }^{7}$, en el que un grupo de ciudadanas y ciudadanos, de forma plural y voluntaria, han dado lugar a un organismo municipal, ratificado en el BOPA (Boletín de la Provincia de Alicante) $)^{8}$, el 30 de septiembre de 2014. Este nuevo órgano ciudadano, que funciona desde finales de 2014, sirve para deliberar, adoptar decisiones y proponer medidas sobre asuntos de interés común que afecten a la ciudadanía y a la gestión del municipio.

BiBLIOGRAFÍA

DELFOUR, C. (2007): España, las autonomías y Europa. Ensayo sobre la invención de nuevos modos de organización territorial y de gobernanza, Editorial TREA, Gijón, 292 p.

FONT, J., MONTERO, J.R. y TORCAL, M. (2006) (editores): Ciudadanos, asociaciones y participación en España, Centro de Investigaciones Sociológicas (CIS), Madrid, $430 \mathrm{p}$.

HERAS HERNÁNDEZ, F. (2002): Entre Tantos. Guía práctica para dinamizar procesos participativos sobre problemas ambientales y sostenibilidad, GEA, Valladolid, $137 \mathrm{p}$.

MARTÍNEZ PUCHE, A (2012): "Análisis de las redes empresariales y su incidencia territorial. Transferencia tecnológica, aprendizaje e innovación", Revista de Estudios Andaluces, $\mathrm{n}^{\circ}$ 29, Sevilla, pp. 17-57.

MARTINEZ PUCHE, A. y CALVO PALOMARES, R. (coords.) (2012): Valoraciones técnicas y repercusiones territoriales sobre el ejercicio profesional del desarrollo local. Presente y futuro, GEOBINDEL-UA, ed. Germania, Alzira, 298 p.

MONTERO, J.R., FONT, J., TROCAL, M. (2006) : Ciudadanos, asociaciones y participación en España, Centro de Investigaciones Sociológicas (CIS), Madrid, $430 \mathrm{p}$.

ZAPATA HERNÁNDEZ, V.M (Dir.) (2008): Guía práctica para El trabajo técnico en desarrollo rural, Extensión Universitaria, Universitat Jaume I, Castellón, 219 p.

7 Está integrado por 38 miembros, más un representante de cada grupo, coalición o partido político que ha obtenido representación en el Ayuntamiento en las últimas elecciones municipales. http://www.etvi.villena.es

8 http://www.villena.es/wp-content/uploads/2014/10/20140930-BOPA-Aprob-def-ReglamForo-E-y-S-Villena.pdf 